International Journal of Agriculture, Environment and Bioresearch

Vol. 5, No. 01; 2020

ISSN: $2456-8643$

\title{
EXPOSURE TO SUB-LETHAL DOSES OF CARBOFURAN INDUCES HEMATOLOGICAL ALTERATIONS IN WISTAR RATS
}

\author{
Olusegun K. Afolabi ${ }^{1 *}$, Adedoja D. Wusu ${ }^{2}$, John O. Fatoki ${ }^{1}$ and Oka S. Ayodeji ${ }^{3}$ \\ ${ }^{1}$ Department of Biochemistry, Faculty of Basic Medical Sciences, Ladoke Akintola University of Technology, \\ Ogbomoso, Nigeria \\ ${ }^{2}$ Department of Biochemistry, Faculty of Science, Lagos State University, Lagos, Nigeria \\ ${ }^{3}$ Department of Medical Biochemistry, Kogi State University, Ayingba, Kogi
}

https://doi.org/10.35410/IJAEB.2020.5478

\begin{abstract}
Carbofuran is a widely used carbamate pesticide that has been detected in ground, surface and rain waters. To assess the toxic effect of carbofuran in this study, Wistar rats numbering twentyeight, were orally exposed to sub-lethal doses of carbofuran at 1/40th, 1/20th, and 1/10th of its LD50. After 50 days of exposure certain hematological parameters were evaluated. A significant decrease $(\mathrm{p}<0.05)$ in red blood cell, hemoglobin, hematocrit, mean corpuscular hemoglobin and mean corpuscular volume was observed in the carbofuran-exposed rats. Meanwhile, the exposure resulted in the elevation of the white blood cells, lymphocytes, eosinophils and neutrophils levels in the rats. However, a mixed trend in the thrombocytic indices (total platelet count, mean platelet volume, pro-calcitonin and platelet distribution width) was observed. The exposure to the pesticide, carbofuran produced microcytic anemia and leukocytosis in the rats, in a non-dose dependent manner.
\end{abstract}

Keywords: carbofuran, hematology, hematotoxicity, thrombocytic indices, leucocyte counts.

\section{INTRODUCTION}

The past decades have seen an increase in the use of pesticides for the improvement of agricultural yield(Jaiswal et al, 2013). Pesticides have also find use in the protection of household and industrial items (Milatovic et al, 2006). The application of these chemicals has toxicological implications for non-target organisms in the environment. The lower toxicities and lesser environmental persistence of some class of pesticides, such ascarbamateshave resulted in their higher application frequency than most other pesticides(Jaiswal et al, 2013).

Carbofuran $(\mathrm{CF})$ is a broad spectrum insecticide, acaricide, and nematicide belonging to the carbamategroup of pesticides and its presence has been reported in nontarget mammalian systems including humans (Hossen et al, 2017). It accumulates in fat depots and exerts adverse effects on organs such as brain, liver, skeletal muscles and heart (de Siqueira et al, 2015; RuizSuárez et al, 2015). It has also been reported to be toxic to the mammalian nervous system with earlier studies establishing that carbofuran could inhibit acetylcholine esterase activity(Gupta et al, 2016). Carbofuran exposure has been found to induce reactive oxygen and nitrogen species, resulting in oxidative stress through the enhancement of malondialdehyde generation and 
alteration of the activities of antioxidant enzymes such as superoxide dismutase, catalase, and glutathione transferase(Hossen et al, 2017). These reactive species and free radicals are responsible for the peroxidation of membrane phospholipids which disrupt the normal function of lipid bilayer, and leading to the development of several pathological conditions.

Detection of carbofuran in ground water and its ingestion through contaminated vegetables and fruits have spurred considerable interest and concern about its use. Since changes in hematological profile can indicate the toxicity of a toxic agent in the body, the present study therefore, investigated the effect of sub-lethal doses of carbofuran on some hematological parameters in Wistar rats.

\section{MATERIALS AND METHODS}

\section{Chemicals}

Commercial grade carbofuran marketed as Furadan ${ }^{\circledR}$ was obtained from IrorunAgbe Agrochemical Company (Ogbomoso, Nigeria).

\section{Animals and treatment}

Twenty eight (28) adult male rats, weighing between 120 and $150 \mathrm{~g}$ were used in this study. The animals were housed at $25 \pm 2{ }^{\circ} \mathrm{C}$ under $12 \mathrm{~h}$ cycles of dark and light. The animals were allowed access to standard laboratory food and water ad libitum. After a one-week acclimatization period, they were divided into four groups of seven rats each: a control group, CT 0 , CT $1 / 40^{\text {th }}$, CT $1 / 20^{\text {th }}$, and CT $1 / 10^{\text {th }}$. The animals orally received $0,1 / 40^{\text {th }}, 1 / 20^{\text {th }}$, and $1 / 10^{\text {th }}$ LD50 of CF for rats, respectively. the oral LD50 for CF is $8 \mathrm{mg} / \mathrm{kg}$ (Steeger \& Branch IV, 2003). The treatment was continued for 50 days. At the end of the experimental period, the rats were sacrificed by cervical dislocation after a light anesthesia with ether. Blood samples were collected through cardiac puncture in separate aliquots containing di-potassium salt of EDTA.

Hematological parameters including, red blood cell count (RBC), hemoglobin $(\mathrm{Hb})$, hematocrit (HCT), red blood cell distribution width (RDW), mean corpuscular volume (MCV), mean corpuscular hemoglobin concentration (MCHC), mean corpuscular hemoglobin (MCH), red cell distribution width-standard deviation (RDW-SD), red cell distribution width-coefficient of variation (RDW-CV), white blood cell count (WBC) and differential leucocytic count, thrombocytic indices [total platelet count (PLT), mean platelet volume (MPV), pro-calcitonin (PCT) and platelet distribution width (PDW)] were analyzed. The analyses were conducted with the use of an automated hematological assay analyzer (Medonic CA 620, Sweden).

\section{Statistical Analysis}

Data were analyzed by one-way analysis of variance, followed by Tukey's multiple comparisons test. Results were presented as mean \pm standard error of means (SEM) and values were considered statistically significant at $\mathrm{p}<0.05$. Data were analyzed using GraphPad Prism for Windows, version 6.01 (GraphPad Software, Inc., San Diego, CA, USA.).

\section{RESULTS}




\section{Red blood cell indices}

Results showing the effect of sub-lethal doses of carbofuran on the erythrocyte indices of rats are presented in Table 1 . After 50 days, RBC count was non-significantly reduced in all the groups $(\mathrm{p}>0.05) . \mathrm{Hb}$ and HCT on the other hand, were significantly decreased by the exposure to carbofuran, although not in a dose-dependent manner $(\mathrm{p}<0.05)$. Mean corpuscular volume $(\mathrm{MCV})$, mean corpuscular hemoglobin $(\mathrm{MCH})$ and the mean corpuscular hemoglobin concentration (MCHC) were also determined in this study. In all the CF-treated groups, MCVand $\mathrm{MCH}$ were lowered by as much as, $17 \%, 15 \%, 19 \%$ and 17\%, 7\% 17\% respectively. The exposure however, increased the MCHC values, though not significantly.

\section{Leucocyte and differential leucocyte counts}

Table 2 depicts the effect of CF exposure on the differential leucocytes counts in the rats. Compared to the control, CF significantly caused an increase in WBC, neutrophils, and lymphocytes counts in the animals $(\mathrm{p}<0.05)$. WBC was increased by $61 \%, 35 \% 71 \%$ and the neutrophils by $209 \%, 181 \% 233 \%$ in the $\mathrm{CF} 1 / 40^{\text {th }}, \mathrm{CF} 1 / 20^{\text {th }}$, and $\mathrm{CF} 1 / 10^{\text {th }}$ groups, respectively. For the lymphocytes, only the CF $1 / 20^{\text {th }}$ and $1 / 10^{\text {th }}$ groups were increased by $32 \%$ and $39 \%$ respectively. Eosinophils were elevated by $\mathrm{CF}$ at the highest dose, $1 / 10^{\text {th }} \mathrm{LD}_{50}$ by $200 \%$. However, with the monocytes, CF modulated the concentrations differently with the low dose, i.e. CF $1 / 40^{\text {th }}$ causing an increase of $34 \%$, while the other two doses, CF $1 / 20^{\text {th }}$ and $\mathrm{CF}$ $1 / 10^{\text {th }}$, decreased the levels by $83 \%$ and $84 \%$ respectively. Basophils were unaffected by exposure to the pesticide.

\section{Thrombocytic indices}

PLT, MPV, and PCT values were all significantly altered in the CF-treated group compared to the control, while PDW was left unchanged (Table 3). PLT in the exposed rats was increased by $83 \%, 47 \%$ and $38 \%$ in the $\mathrm{CF} 1 / 40^{\text {th }}, \mathrm{CF} 1 / 20^{\text {th }}$, and $\mathrm{CF} 1 / 10^{\text {th }}$ groups, respectively. Similarly, PCV was elevated by $76 \%, 21 \%$ and $21 \%$, respectively. Meanwhile, the CF $1 / 40^{\text {th }}$ group displayed no adverse effect of CF on PCT but reduced this index by more than $10 \%$ in the other two groups.

\section{DISCUSSION}

The widespread use of pesticides results in a number of adverse health effects in both humans and animals. Derangement in hematological parameters is indicative of the toxic effects of foreign compounds such as pesticides, as well as, changes in physiological and pathological status of an organism (Stoytcheva, 2011). Several studies have utilized hematological changes as a biomarker of pesticide exposure and also for the evaluating the interaction between a toxic agent and biological system (Da Cuna et al, 2011). Generally, inducement of non-specific immunity by a pesticide leads to alterations in hematological parameters (Aroonvilairat et al, 2015). Carbofuran exposure in the present study resulted in remarkable hematological alterations. 
Carbofuran caused a reduction in $\mathrm{RBC}, \mathrm{HCT}$, and $\mathrm{Hb}$ in our study. These alterations may result from the disruptive action of the pesticide on the red cell membranes (Ramesh \& Saravanan, 2008). Furthermore, the lysing or shrinkage of red blood cells caused by the action of the pesticide on the erythropoietic tissue and the suppression of erythropoiesis may lead to a reduction in red blood cell, hemoglobin and hematocrit (Saravanan et al, 2011). The decrease in $\mathrm{Hb}$ and Hct values in our study indicates a non-specific immune response of the rats to the insecticide. It is also reflective of the rats' defensive reaction against pesticide stress (Narra, 2016). The observed decrease in MCV and MCH in the treated groups suggested shrinkage of the RBCs. It may also be due to an increase in the level of immature RBCs in the circulation (Saravanan et al, 2011). The MCH reflects $\mathrm{Hb}$ content and $\mathrm{Hb}$ rate to $\mathrm{RBC}$ which were reduced following carbofuran exposure (Hossen et al, 2017). The decrease indicates microcytic normochromic anemia in the exposed rats (Adhikari et al, 2004). The observed increase in MCHC value, though non-significant, indicates an upsurge in $\mathrm{Hb}$ synthesis which could be a compensatory mechanism for the depleted $\mathrm{Hb}$ concentration in the carbofuran-exposed rats. The reduction in RDW-SD and RDW-CV, along with $\mathrm{RBC}, \mathrm{Hb}$, and Hct support the suggested of an up-regulation of the erythropoiesis in the bone marrow. This might have resulted in the production of impaired red cells or atrophied erythrocytes which would have been destroyed in circulation.

The deleterious effects of carbofuran on the total WBC, neutrophils, lymphocytes, and monocytes were evident in this study. The WBC count is a biomarker of systemic inflammation, as the cells are involved in the regulation of immunological function (Farhangi et al, 2013). A significant increase in total WBC, neutrophils, and lymphocytes levels, along with a significant increase in the platelet count were observed in the carbofuran-exposed rats. This indicates either a protective mechanism against the pesticide or the activation of the rat immune system against the carbofuran-induced stress. An increased WBC count can be adduced to an increased antibody production in order to ameliorate pesticide-induced toxicity (Joshp et al, 2002). Leukocytosis in this study may occur as a result of increased leukocyte mobilization, reflective of the severity of causative stress condition (Celik et al, 2009). Other pesticides have been reported to stimulate immune functions by increasing WBC levels, indicating the activation of defense and immune system where oedema and inflammation have been induced (Yousef et al, 2003). The increase in leucocytes was particularly evident in the case of lymphocytes which could have resulted from the stimulation of lymphopoietic process in the rats. Leukocytosis has been demonstrated in animals intoxicated with pesticides and has been suggested to be due to the mobilization of the immunological system and/or a shift in the leucocytic pool from the spleen to peripheral blood (Haratym-Maj, 2003). Non-specific irritation caused by the toxicant and/or its metabolites may induce the production and release of inflammatory mediators like prostaglandins thatproduceneutrophilia. Neutrophilia can lead to enhanced release of mature neutrophils from the bone marrow and the subsequent demargination, contributing to the circulating pool (Khan et al, 2013). A significant increase in PLT counts was found in all the CF-treated groups. Pesticides can induce histopathological damage (Afolabi et al, 2018) and such damage can increase the production of PLT, as well as WBC as seen in our study.

\section{CONCLUSION}


Vol. 5, No. 01; 2020

ISSN: $2456-8643$

It can thus, be concluded that sub-lethal doses of carbofuran elicited hematological alteration, which was characterized by microcytic normochromic anemia and leukocytosis. Also, the modulatedhematotoxic response induced by the pesticide in the rats was not dose-dependent. The data from this study further provide evidence of the toxic effect of carbofuran.

\section{REFERENCES}

Adhikari S, Sarkar B, Chatterjee A, Mahapatra C,Ayyappan S. 2004. Effects of cypermethrin and carbofuran on certain hematological parameters and prediction of their recovery in a freshwater teleost, Labeo rohita (Hamilton). Ecotoxicology and Environmental Safety58(2), 220-226.

Afolabi OK, Wusu AD, Ugbaja R, Fatoki JO.2018. Aluminium phosphide-induced testicular toxicity through oxidative stress in Wistar rats: Ameliorative role of hesperidin. Toxicology Research and Application 2, 2397847318812794.

Aroonvilairat S, Kespichayawattana W, Sornprachum T, Chaisuriya P, Siwadune T, Ratanabanangkoon K.2015. Effect of pesticide exposure on immunological, hematological and biochemical parameters in Thai orchid farmers - a cross-sectional study. International Journal of Environmental Research and Public Health12(6), 5846-5861.

Celik I, Yilmaz Z, Turkoglu V. 2009. Hematotoxic and hepatotoxic effects of dichlorvos at sublethal dosages in rats. Environmental Toxicology: An International Journal24(2), 128-132.

Da Cuna RH, Vazquez GR, Piol MN, Guerrero NV, Maggese MC,Nostro FLL. 2011. Assessment of the acute toxicity of the organochlorine pesticide endosulfan in Cichlasoma dimerus (Teleostei, Perciformes). Ecotoxicology and Environmental Safety74(4), 1065-1073.

de Siqueira A, Salvagni FA, Yoshida A S, Gonçalves-Junior V, Calefi AS, Fukushima AR, de Souza Spinosa H, Maiorka PC.2015. Poisoning of cats and dogs by the carbamate pesticides aldicarb and carbofuran. Research in Veterinary Science102, 142-149.

Farhangi MA, Keshavarz SA, Eshraghian M, Ostadrahimi A, Saboor-Yaraghi AA.2013. White blood cell count in women: relation to inflammatory biomarkers, haematological profiles, visceral adiposity, and other cardiovascular risk factors. Journal of Health, Population, and Nutrition31(1), 58.

Gupta VK, Pathak A, Siddiqi NJ,Sharma B.2016. Carbofuran modulating functions of acetylcholinesterase from rat brain in vitro. Advances in Biology2016.

Haratym-Maj A. 2003. Hematological alternations after pyrethroids poisoning in mice. Annals of Agricultural and Environmental Medicine9(2), 199-206.

Hossen MS, Tanvir E, Prince MB, Paul S, Saha M, Ali MY, Gan SH, Khalil MI,Karim N.2017. Protective mechanism of turmeric (Curcuma longa) on carbofuran-induced hematological and hepatic toxicities in a rat model. Pharmaceutical Biology55(1), 1937-1945.

Jaiswal SK, Siddiqi NJ,Sharma B. 2013. Carbofuran induced oxidative stress in rat heart: ameliorative effect of vitamin C. ISRN Oxidative Medicine2013.

Joshp P, Bose M,Harish D. 2002. Changes in certain haematological parameters in a siluroid cat fish Clarias batrachus (Linn) exposed to cadmium chloride. Pollution Research21(2), 129131.

Khan AM, Dubey N, Raina R, Singh G, Beigh SA. 2013. Toxic effects of deltamethrin and fluoride on hematological parameters in rats. Fluoride46(1), 34-38. 
Milatovic D, Gupta RC,Aschner M. 2006. Anticholinesterase toxicity and oxidative stress. The Scientific World Journal6, 295-310.

Narra MR. 2016. Single and cartel effect of pesticides on biochemical and haematological status of Clarias batrachus: a long-term monitoring. Chemosphere144, 966-974.

Ramesh M, Saravanan M.2008. Haematological and biochemical responses in a freshwater fish Cyprinus carpio exposed to chlorpyrifos. International Journal of Integrative Biology3(1), 80-83. Ruiz-Suárez N, Boada LD, Henríquez-Hernández LA, González-Moreo F, Suárez-Pérez A, Camacho M, Zumbado M, Almeida-González M, del Mar Travieso-Aja M,Luzardo OP.2015. Continued implication of the banned pesticides carbofuran and aldicarb in the poisoning of domestic and wild animals of the Canary Islands (Spain). Science of the Total Environment505, 1093-1099.

Saravanan M, Kumar KP,Ramesh M.2011. Haematological and biochemical responses of freshwater teleost fish Cyprinus carpio (Actinopterygii: Cypriniformes) during acute and chronic sublethal exposure to lindane. Pesticide Biochemistry and Physiology 100(3), 206-211.

Steeger T,Branch IV ER.2003. Revised EFED Risk Assessment of Carbaryl in Support of the Reregistration Eligibility Decision (RED) 53 Special Review and Reregistration Division (7508C).

Stoytcheva M.2011.Pesticides in the modern world: effects of pesticides exposureBoD-Books on Demand.

Yousef M, El-Demerdash F, Kamel K,Al-Salhen K. 2003.Changes in some hematological and biochemical indices of rabbits induced by isoflavones and cypermethrin. Toxicology189(3), 223234. 
Table 1. Effect of carbofuran on the hematological parameters of rats

\begin{tabular}{|c|c|c|c|c|c|c|c|c|c|c|c|c|c|c|c|c|}
\hline & $\begin{array}{l}\text { RBCs } \\
\left(\times 10^{12} / \mathrm{L}\right.\end{array}$ & & $\mathrm{Hb}(\mathrm{g} /$ & & HCT & & $\begin{array}{l}\mathrm{MCV} \\
\text { (fL) }\end{array}$ & & $\begin{array}{l}\mathrm{MCH} \\
\text { (pg) }\end{array}$ & & $\begin{array}{l}\text { MCHC } \\
(\mathrm{g} / \mathrm{dL})\end{array}$ & & RDW- & & RDW- & \\
\hline \multirow[t]{2}{*}{ Control } & 8.31 & \pm & 16.87 & \pm & 61.07 & \pm & $71.63 \pm$ & & 20.40 & \pm & 27.70 & \pm & 0.20 & \pm & 64.53 & \pm \\
\hline & $0.17^{\mathrm{a}}$ & & $0.13^{\mathrm{a}}$ & & $1.66^{\mathrm{a}}$ & & $3.12^{\mathrm{a}}$ & & $1.37^{\mathrm{a}}$ & & $0.55^{\mathrm{a}}$ & & $0.01^{\mathrm{a}}$ & & $4.70^{\mathrm{a}}$ & \\
\hline CF & 8.58 & \pm & 14.57 & \pm & 50.80 & \pm & 59.17 & \pm & 16.97 & \pm & 28.67 & \pm & 0.17 & \pm & 46.53 & \pm \\
\hline $1 / 40^{\text {th }}$ & $0.23^{\mathrm{a}}$ & & $0.48^{\mathrm{b}}$ & & $1.57^{\mathrm{b}}$ & & $0.42^{\mathrm{b}}$ & & $1.61^{b}$ & & $0.22^{\mathrm{a}}$ & & $0.00^{\mathrm{bc}}$ & & $0.17^{\mathrm{bc}}$ & \\
\hline CF & 7.14 & \pm & 15.52 & \pm & 51.98 & \pm & 61.00 & \pm & 18.90 & \pm & 28.75 & \pm & 0.18 & \pm & 53.15 & \pm \\
\hline $1 / 20^{\text {th }}$ & $0.35^{\mathrm{b}}$ & & $0.16^{\mathrm{b}}$ & & $0.40^{\mathrm{b}}$ & & $0.45^{\mathrm{b}}$ & & $0.28^{c}$ & & $0.43^{\mathrm{a}}$ & & $0.00^{\mathrm{b}}$ & & $0.74^{\mathrm{b}}$ & \\
\hline $\mathrm{CF}$ & 6.90 & \pm & 15.57 & \pm & 46.90 & \pm & 58.23 & \pm & 16.97 & \pm & 29.20 & \pm & 0.16 & \pm & 41.97 & \pm \\
\hline $1 / 10^{\text {th }}$ & $0.17^{\mathrm{c}}$ & & $0.25^{\mathrm{b}}$ & & $0.75^{\mathrm{c}}$ & & $1.60^{\mathrm{b}}$ & & $0.29^{b}$ & & $0.29^{\mathrm{a}}$ & & $0.00^{c}$ & & $1.06^{\mathrm{c}}$ & \\
\hline
\end{tabular}

Each value represents the mean \pm SEM of 7 rats. Values within a column with different alphabets are significantly different at $\mathrm{p}<0.05$.

Table 2: Effect of carbofuran treatment on the total and differential leucocytes counts of rats

\begin{tabular}{|c|c|c|c|c|c|c|}
\hline & WBCs & Lymphocytes & Neutrophils & Monocytes & Eosinophils & Basophils \\
\hline Control & $6.44 \pm 0.12^{\mathrm{a}}$ & $4.61 \pm 0.18^{\mathrm{a}}$ & $0.75 \pm 0.14^{\mathrm{a}}$ & $1.29 \pm 0.10^{\mathrm{a}}$ & $0.09 \pm 0.01^{\mathrm{a}}$ & $0.06 \pm 0.01^{\mathrm{a}}$ \\
\hline CF $1 / 40^{\text {th }}$ & $\begin{array}{l}10.38 \\
0.38^{b}\end{array}$ & $4.31 \pm 0.25^{\mathrm{b}}$ & $2.39 \pm 0.13^{b c}$ & $\begin{array}{l}1.73 \\
0.04^{\mathrm{b}}\end{array}$ & $0.13 \pm 0.01^{\mathrm{a}}$ & $0.06 \pm 0.01^{\mathrm{a}}$ \\
\hline CF $1 / 20^{\text {th }}$ & $8.67 \pm 0.18^{c}$ & $6.10 \pm 0.10^{c}$ & $2.10 \pm 0.03^{b}$ & $0.22 \pm 0.04^{c}$ & $\begin{array}{l}0.17 \\
0.01^{\mathrm{ab}}\end{array}$ & $0.08 \pm 0.00^{\mathrm{a}}$ \\
\hline $\mathrm{CF} 1 / 10^{\text {th }}$ & $\begin{array}{l}11.02 \\
0.36^{\mathrm{b}}\end{array}$ & $6.42 \pm 0.34^{\mathrm{c}}$ & $2.59 \pm 0.11^{\mathrm{c}}$ & $0.21 \pm 0.03^{\mathrm{c}}$ & $\begin{array}{l}0.27 \\
0.05^{\mathrm{b}}\end{array}$ & $0.05 \pm 0.02^{\mathrm{a}}$ \\
\hline
\end{tabular}

Each value represents the mean \pm SEM of 7 rats. Values within a column with different alphabets are significantly different at $\mathrm{p}<0.05$.

Table 3: Effect of carbofuran treatment on the thrombocytic indices of rats

\begin{tabular}{|c|c|c|c|c|c|}
\hline & $\operatorname{PLT}\left(10^{9} / \mathrm{L}\right)$ & MPV (fL) & PDW $(\mu \mathrm{n}$ & & PCT (\%) \\
\hline Control & $405.70 \pm 41.99^{a}$ & $8.60 \pm 0.07^{\mathrm{a}}$ & $\begin{array}{l}15.78 \\
0.09^{\mathrm{a}}\end{array}$ & \pm & $3.49 \pm 0.36^{\mathrm{a}}$ \\
\hline CF $1 / 40^{\text {th }}$ & $742.30 \pm 34.09^{b}$ & $8.27 \pm 0.08^{\mathrm{a}}$ & $\begin{array}{l}15.67 \\
0.04^{\mathrm{a}}\end{array}$ & \pm & $6.12 \pm 0.21^{b}$ \\
\hline CF $1 / 20^{\text {th }}$ & $596.70 \pm 37.00^{c}$ & $7.35 \pm 0.16^{b}$ & $\begin{array}{l}15.75 \\
0.07^{\mathrm{a}}\end{array}$ & \pm & $4.23 \pm 0.30^{\mathrm{a}}$ \\
\hline CF $1 / 10^{\text {th }}$ & $560.00 \pm 19.94^{\mathrm{c}}$ & $7.60 \pm 0.13^{b}$ & $\begin{array}{l}15.83 \\
0.15^{\mathrm{a}}\end{array}$ & \pm & $4.22 \pm 0.33^{\mathrm{a}}$ \\
\hline
\end{tabular}

Each value represents the mean \pm SEM of 7 rats. Values within a column with different alphabets are significantly different at $\mathrm{p}<0.05$. 